\title{
Electric vehicles from novelty to controversy: Analyzing environmental and fairness claims in open-ended survey questions
}

\author{
Endre Tvinnereim ${ }^{1}$ and Gregory Ferguson-Cradler ${ }^{2}$ \\ ${ }^{1}$ Department of Administration and Organization Theory, University of Bergen \\ ${ }^{2}$ Department of Law, Philosophy and International Studies, Inland Norway University of Applied Sciences
}

August 26, 2020

\begin{abstract}
The transportation sector accounts for one of the highest shares of greenhouse gas (GHG) emissions globally, and a transition away from fossil fuels is required to reach globally agreed temperature goals for this century. Electrification constitutes one likely option for such a transition, yet public acceptance could represent a major barrier. While past research has produced some knowledge about conditions for early adoption, less is known about acceptance in the context of mass-market penetration. Furthermore, existing research is limited by survey design and unrepresentative data sets.We address these problems using a novel online survey approach combining open-ended and fixed-response questions to examine common topics mobilized by survey respondents, valence and meanings of particular words within those topics, and how words and topics map onto approval and satisfaction with electric vehicles. Our results show high overall support for electrification of personal cars but notes concerns related to the environment (notably the production and disposal of batteries) and around distributional effects that need to be addressed.
\end{abstract}

\section{Introduction}

Energy-economy-climate models indicate that decarbonization of the electricity supply sector combined with electrification of key end-use sectors can be a key factor in limiting global warming to $1.5^{\circ} \mathrm{C}$ this century. Electrification in end-use sectors notably covers industry, transportation, and households, and policies to promote it may include both economic incentives and banning non-electric gear (van Vuuren et al. 2018). There is 
limited research, however, on public acceptance of policies to promote such large-scale electrification. Steg (2018) have recently called for more research on the "conditions under which high electrification rates and integrated energy systems are acceptable to the public (760)."

One of the key areas in need of electrification to meet a $1.5 / 2 \mathrm{C}$ require target is transportation. With electrical vehicle (EV) technology relatively new and, as yet, having only a modest market share, there are many answered questions about what obstacles to uptake there might be when EVs are are more widespread. Norway has the highest EV penetration in the world, with 9.3 percent of registered passenger cars being fully electric by the end of 2019 (Statistics Norway 2020). Therefore, the case of Norway might offer lessons and serve as a possible leading indicator for challenges that will be met across the world in the coming years. Importantly, the issue is not just that of expanding electric technologies as fast as possible. Public protest and anger against inequalities of environmental legislation and policies - such as the gilets jaunes in France or congestion-pricing opponents in Norway - increasingly serve as a reminder that policies to combat climate change cannot be successful without considerations of fairness and justice (Sovacool et al. 2019; Tvinnereim et al. 2020).

This paper looks at public opinions and perceptions of electrical vehicles in a market where they have long ceased to be a novelty and, in fact, are approaching a majority of new car sales. What are the key issues voiced by residents in a country where the market for electric vehicles is so significant and continues to expand rapidly? Particularly of interest are fairness-related claims - how do people articulate questions of justice particularly in relation to the state's economic and regulatory support for electric vehicles? Can we categorize support and opposition to electrical vehicles in ways that might aid states in designing policies to reduce carbon emissions? More generally, we seek to mobilize recent literature in political science and environmental psychology to map the terrain of public opinion looking at different modes of support for and criticism of electric vehicles. We seek to identify and classify the attributes of consumption decisions outlined by Noppers et al. (2014) and further investigate and employ the normative and justice-related discussion of Sovacool et al. (2019) in a market in which EVs are becoming increasingly more widespread.

The data comes from a unique web-based survey source among Norwegian households giving open-answer textual responses to questions of sentiment toward electric vehicles with a wide array of associated co-variables. To exploit this source, we employ a mixedmethods approach to best leverage the small-N aspects of our sample $(\sim 25,000$ total words from over 3,000 respondents) while also taking advantage of co-variables and leveraging possibilities of quantitative computational text analysis.

The argument will proceed as follows. A brief overviews of uptake and public opinion 
of new $\mathrm{CO}_{2}$ reducing technologies in the transportation sector follows. A subsequent methods section gives a brief summary of quantitative text analysis and social scientific methods for machine and human reading of text corpora and an overview of methods used in this study. After this we present and explore our data from the Norwegian Citizens Panel. A discussion of the data with reference to the central questions of this article will be followed by a concluding section.

\section{Public acceptance of new transportation solutions}

Public acceptance and behaviour constitute major barriers to the adoption of sustainable transport (Sims and Schaeffer 2014) However, the literature on public acceptance and behaviour has several limitations, both thematic and methodological. First, while some of the factors affecting early adoption of more sustainable transport options are known, especially in the case of electric vehicles, less attention has been devoted to barriers and challenges that emerge as adoption becomes more widespread and the effects of policies are more widely perceived. The current literature links public preferences about electric vehicles to cost, functionality, familiarity and personal values (Barth, Jugert, and Fritsche 2016; Biresselioglu, Demirbag Kaplan, and Yilmaz 2018; Sierzchula et al. 2014; Krause et al. 2016). Personal values (environmental care, altruism) increase the likelihood of choosing zero-emission vehicles (Bockarjova and Steg 2014; Rezvani, Jansson, and Bodin 2015). Owning and driving an EV may itself change habits and raise awareness about transportation and energy issues (Ryghaug and Toftaker 2014).

Barth, Jugert, and Fritsche (2016) argue that "norms and collective efficacy have equal or even stronger effects on acceptance than cost-related factors" in the case of EV adoption surveys carried out in Germany. However, the relationship between social identity, norms, and financial factors may shift as adoption increases and the market matures. Due to the still-early stages of EV diffusion, there is a gap in knowledge about issues related to equity and distributional effects in this context. As relatively expensive EVs become more widely used by people who can afford them, while receiving benefits such as free toll roads, driving in bus lanes and free parking, equity concerns are likely to increase. In tabloid terms, some may then ask whether EV support measures imply a "transition for the rich". A transition away from fossil fuels without compensatory measures may lead to "considerable economic and social stress to occur within car-dependent suburbia" (Dodson, Li, and Sipe 2018, 246) and likely also among rural residents.

Better data collection tools are needed to assess large-scale opinion movements and behaviour. Many of the questions related to sustainable transport (e.g., new technologies, sharing, comprehensive land use plans) are multifaceted and contested; respondents have potentially unformed attitudes towards them. While traditional, "closed-ended" 
survey questions severely limit the response options available to the participant, "openended" questions permit "the respondent to use his or her own frame of reference in determining a response, even if this might seem inappropriate or 'irrational' to the survey designer or analyst" (Stoneman, Sturgis, and Allum 2013, 853). Notably, combinations of probability-sample population panels with emerging methods such as open-ended survey questions and conjoint experiments are needed to provide a fuller picture of the public's images of and views on the sustainability transition. Given the rapid increase in the volume of electronic text available, there is a great potential for automated text analysis to be integrated into social science research methods (discussed below). Nevertheless, few studies analyse large-scale textual data in the field of sustainable transport, missing potentially crucial information.

\subsection{Barriers to EV uptake}

Barriers to EV uptake include cost, inconvenience, lack of charging infrastructure, and habit. Bubeck, Tomaschek, and Fahl (2016) find that EVs are not cost-competitive in Germany and argue that a buyer's premium of $10,700 €$ would have been needed to reach government targets of one million EVs in Germany by 2020. EVs have also historically been characterized by short ranges and small sizes, although recent changes have partially remedied these problems. Long charging times, compared to the speed of filling a tank with gasoline, constitute another inconvenience. "Range anxiety" relates to uncertainty about reaching one's goal before the battery runs out, as well as to being able to find (non-occupied) charging stations when needed. More broadly, lack of familiarity with the concept of EVs likely makes many consumers stick with fossil-fueled models when purchasing a new car.

A significant strand of research has shown that environmental concerns can play a significant role in individual decision-making about consumption (Steg and De Groot 2012). This suggests that consumers who prioritize the environment and personally rate global warming a important matter will be more willing to adopt technology that might be more inconvenient and/or more expensive (Noppers et al. 2014).

While cost and inconvenience constitute barriers to adoption, Noppers et al. (2014) argue that symbolic motives for choosing environmentally friendly alternatives are more important than generally recognized. Symbolic motives are defined as reflecting "the (positive or negative) outcomes of the ownership and use of the sustainable innovation for one's (self-)identity and social status" (53). As highlighted by mid-century symbolic interactionist sociologists, it is not just an individual's actions with regard to her environment that influence decision-making. Individuals take action within communities of other actors who observe each other. Actions have meanings that are socially mediated and occur within view of others in society (Joas and Knöbl 2014, ch. 6). Erving Goffman famously 
argued that people purposely attempt to control or guide perceptions of themselves in the eyes of others by engaging in practices symbolizing certain things and not others (Goffman 1990 [1956]).

Adopters of sustainable, low-carbon products might be motivated first and foremost by the desire to advertise their ecological virtue or because being environmentally-friendly is a core part of their identity. Accordingly, symbolic motives for adopting sustainable innovations may involve signaling one's innovativeness, social virtuousness, independence, intelligence, or unique personality (Noppers et al. 2014). Like Veblen's conspicuous consumers who seek to advertise their wealth and power by flaunting consumption of expensive luxury goods and service, "instrumental drawbacks" such as increased price for similar performance or added inconvenience might even strengthen symbolic motives Veblen (2005 [1899]). This suggests an important role for performative public representation of EVs in aiding or holding back adoption.

In their study of electric car adaptation, Noppers et al. (2014) seek to determine how much uptake of electric vehicles can be traced to instrumentalist, environmental and symbolic motivation among consumers. They do not, however, consider negative symbolic effects or decisions that have conflicting valences and valuations in different people.

This study looks at cases in electric car adaptation in which symbolic virtue has been significantly contested. At more advanced stages of diffusion, public concerns regarding issues such as fairness and adverse environmental impacts may be harder to overcome than problems related to inconvenience. In the case of Norway, many of the instrumental problems are rapidly diminishing thanks to technological advancements, direct state subsidies, and investment in infrastructure. Costs are increasingly similar between electric and fossil-fuel consuming cars and the inconvenience of driving electric are fewer and fewer. At the same time, concern in Norway about global warming is widely shared across the Norwegian political spectrum, though individual prioritization does, of course, vary. In this context symbolic issues around electric vehicles increasingly take center stage.

Indeed, recent studies have begun discussing normative aspects of EV policies, notably related to distributive issues (are EVs mainly for the rich?), environmental externalities (such as battery production and decommissioning), and rural vulnerability (Sovacool et al. 2019). These types of concern are often expressed among experts but it remains a question to what extent they are reflected among the public. Furthermore, barriers related to adoption are generally tied to the question of what determines the propensity of individual households to adopt an EV. At the level of society, however, questions relate to the sustainability of EV promotion policy when facing resistance due to factors such as fairness concerns, environmental opposition to continued car use, and concerns about manufacturing, notably safe disposal of batteries. 


\section{Data and Methods}

\subsection{Data}

The data for this article come from the tenth wave of the Norwegian Citizen Panel (NCP), conducted between October 31 and November 23, 2017. The NCP is an online, probabilitysample survey platform owned by the University of Bergen with participants drawn at random from the Norwegian population registry ${ }_{1}^{1}$ Participants are invited to take part in studies two or three times per year. Data generated through the survey is used exclusively for academic research.

Of 6,765 total survey respondents, 3,286 were asked two questions regarding electric vehicles. The open-ended questions relevant to the current study was:

What is the first thing you think of when you hear or read the word "electric car"? Please write down the first thing that comes to mind. We are looking for any type of answer, ideally a couple sentences or simply a couple of words if that works better for you.

Norwegian original: Hva er det første du tenker på når du hører eller leser ordet «elbil» (eller «elektrisk bil»)? Vennligst skriv ned det første du kommer på. Vi ønsker alle typer svar, gjerne et par setninger, eller bare noen få ord om det passer bedre for deg.

Respondents were also asked to rate their opinions of electric cars on a scale from 1 to 7 , with 1 extremely negative and 7 extremely positive:

How positive or negative is your general opinion of electrical cars?

Norwegian original: Hvor positiv eller negativ er din oppfatning om elbiler, rent generelt?

We also make use of background variables available for respondents including age, gender, residence location, education level, political orientation, and others.

\subsection{Methods}

\subsubsection{Quantitative Text Methods}

Computational text analysis has rapidly become a key methodology in the social sciences over the past decade and a half. Many of the quantitative text methods put to use in the social sciences have their origin in natural language processing (NLP), itself an interdisciplinary field at the intersection between information retrieval, usually housed in computer science departments, and computational linguistics (Jurafsky and Martin

1. For information see the survey website www.medborger.uib.no. 
2014). One common use of NLP in the social sciences has been sentiment classification using algorithms to extract negative or positive sentiment from a text. Approaches are often differentiated between those requiring training on a sample data set before they are applied to out-of-sample data (supervised learning) and unsupervised learning which are methods immediately applied to out-of-sample data without training on data where the outcomes of interest are known. NLP has further developed methods that bridge supervised and unsupervised approaches involving, for instance, selecting "seed words" by hand, which are highly sensitive to context, to represent opposite ends of sentiment "poles", say, from good to bad. (Jurafsky and Martin 2014, ch. 19) These methods also work with meta-data on sentiment that is scalar, as in the case of online reviews between 1 and 5 stars or, as in this paper, between 1 and 7. One example of this approach is (Potts 2010) where words are represented by a tuple containing the number of entries as rating levels (thus a five-star rating system will yield a five-tuple), with each number expressing the frequency with which that word appears in reviews with the given rating.

Among the many methods developed in the last decades in these fields, several others are of key importance to this study of difference between corpora. One widely used means of comparing and contrasting texts is that of cosine difference. The methods relies on each document of a corpus being represented as a numerical vector. There are numerous ways to represent texts, the simplest - those used here - reduce a document to a list of word frequencies, with frequency represented either as a simple count, Boolean indicating presence or absence of a given word, term-frequency adjusted for document length or term-frequency inverse-document frequency of each term. $[$ A cosine distance, otherwise called a normalized dot product, is a simple method to determine similarity of two vectors (Jurafsky and Martin 2014, ch. 6).

Two measures from corpus linguistics are also utilized below. First, keyness analysis, which emphasizes the vocabulary that most differentiates texts from one group in comparison to the other, also brings out the major topics that differentiate those that view EVs highly and those that do not. This value is calculated by taking all words in a corpus and computing their relative frequency (likelihood to appear) and then measuring word distributions from subsets of the corpus, statistically calculating how likely it was that terms were drawn from the same distribution as for the corpus as a whole using chi-squared test of statistical significance (Scott and Tribble 2006). This method is a statistical descendent of the keywords or Begriffsgeschichte approaches made especially famous by Raymond

2. Formally, tf-idf is computed as tf-idf $=\mathrm{tf}$. idf in which tf $=f_{t, d} /\left(\sum_{t^{\prime} \in d} f_{t^{\prime}, d}\right.$ and idf $=\log \frac{N}{n_{t}}$ where frequency $f$ is calculated for every term $t$ in document $d$ in the total number of documents $N$ in the corpus with $n_{t}$ thus denoting number of documents containing term $t$. In words, tf-idf as computed here is the term frequency adjusted for document length multiplied by the natural logarithm of the total number of documents in a corpus divided by the number containing the given term (Schütze, Manning, and Raghavan 2008, 117-119). 
Williams and Reinhardt Koselleck (Koselleck and Presner 2002; Williams 2014 [1976]) : $_{3}^{3}$ Finally, type-token ratios are used to measure lexical diversity of texts which are, at their simplest, total number of different words (terms) used in a text divided by the number of total words (tokens).

\subsubsection{Combining textual and numerical response data}

We combine our text data with numerical response data, primarily the variable denoting positive/negative attitudes toward EVs, in three ways. First, to assess the extent to which word choice correlates with attitudes toward EVs, we rank word frequencies within subsets of the sample defined by responses to the 1-7 attitudinal scale. Second, we invert this method and segment the sample into groups according to whether they use given frequent words, and calculate the average opinion level for each of the words. Third, we use keyness analysis, document similarity measurement, and other tools from NLP to visualize and quantify differences in words and topics by opinion of EVs is through "keyness" analysis, as explained in the methodological section above.

\subsubsection{Qualitative topic assignment}

Another extremely popular method of computational text analysis in the social sciences is topic modeling. Topic models are a class of generative, Bayesian probabilistic models that assume documents are mixtures of topics drawn from a distribution, which in turn is generally optimized to minimize the mixture of topics in any given document. ${ }^{4}$ While increasingly popular, our data of a relatively small corpus based on individual "documents" (survey responses) often no more than one word in length proved to be a poor match for this method. This study thus relies on NLP methods. Using these techniques we identify several categories and words which we investigate through close reading, which in turn further informs ways in which computational methods can be used in a method similar to that outlined by Nelson (2020). The result is a mixed methods approach to analysing relatively small corpora of open-ended survey data that leverages computational text methods to direct and increase efficiency of close readings.

Especially in such traditionally qualitative disciplines such as sociology, anthropology, history, and literary studies, some trepidation has been involved with the moving of computational text methodologies into practitioners' disciplinary toolkits (Marche 2012). One of the most controversial facets of computational text analysis is the difficulty of capturing meaning and assuming continuity of meaning across texts and contexts. Thus, in most social sciences of an interpretive bent, the message is clear - computers do not and will not substitute for human readers, computational techniques must be used to augment,

3. See Stubbs (2010) for an overview.

4. For a helpful, high-level overview of topic modeling, see (Blei 2012). 
not replace, close, deep readings. In this context, the idea of blended readings has been proposed, whereby computational steps - especially useful in discovering structures or patterns in text and perhaps confirmation of patterns or hypotheses - are blended with qualitative readings of substantive or representative portions of text. (Grimmer and Stewart 2013; Lemke et al. 2016; Nelson 2020) Such has been suggested, for example, with corpora that are so massive that a single human, or even team of researchers, could not hope to be able to read them in a reasonable amount of time. But, as argued in this paper, even with corpora that are small and could - and have been - easily read by researchers in their entirety, computational models can elucidate structure that a human reader is not necessarily able to pick up and, especially in the presence of meta-data, can helpfully be used to discover, analyze and visualize differences in text with respect to co-variables.

The nature of our data source also means that verification by hand, always desirable, is even more crucial. As the survey question asked of respondents took the form of "what comes to mind", responses were often incomplete sentences of individual words representing totally different ideas. To pick one example at random, one survey-taker responded "environmentally-friendly, future, range, worry." These terms seem to be independent, free-associations, which makes close reading imperative. The inability to use topic models encouraged us to use NLP methods that are frequently passed over by social scientists in the rush to use more popular and complex algorithms. We believe that these other methods - including simple word frequencies, keyness, collocation analysis (co-occurrence), and simple cosine distance - can aid researchers not only when working with a corpus that does not allow topic modeling but might also be integrated in topic model analysis. These methods have the advantage that they are all relatively simple and give intuitive results.

\section{Results}

\subsection{Summary co-variate statistics}

To begin with, survey results give some indication of who actually owns electric vehicles in Norway and their reported reasons for ownership. The most common age groups to own an electrical car were between $36-45$ and $46-55$. In both groups $13 \%$ of respondents reported EV ownership. Those younger than 36 (18 is the minimum age for participation in the survey) and between 56-65 reported about half that rate while ownership among the oldest segments of the population were significantly lower. There is no statistical difference in ownership of electric cars across categories of gender, level of education,

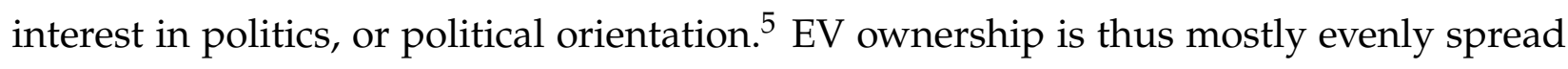

5. The only region of Norway reporting statistically significant different levels of EV ownership is North Norway. 
out across the Norwegian population $\sqrt{6}$

Three factors are cited by more than $30 \%$ of owners as reasons for purchasing an EV. Two are instrumental reasons: $76 \%$ cite cheap fuel costs and $61 \%$ list exemption from road tolls as reasons for owning EVs. The single most cited reason, however, given by $81 \%$ of EV drivers, is that it is good for the environment. It is difficult, however, to get at "symbolic" characteristics of ownership through direct questions to owners. We take this up in our analysis of text responses.

Considering opinions toward EVs rather than EV ownership itself, difference across categories seems to be slightly more pronounced. Mean opinion on EVs among respondents on a 1-7 scale (1 representing extremely unfavorable opinion and 7 being extremely favorable) is 4.98. Across the political spectrum, those at each political extreme have slightly lower opinions of EVs. Those on the far left of the political spectrum (on a 1-11 scale) rate them slightly lower than the mean (statistically significant at a $90 \%$ level) while those placing themselves in the three categories furthest to the right report opinion levels of $4.70,4.41$, and 3.76 , all statistically significant from the mean at a $95 \%$ confidence level. Thus dimmer views of EVs are clearly associated with more right-leaning political orientation.

In regional preferences, those resident in the capital city of Oslo have the highest opinion of EVs, giving them a mean of 5.17 closely followed by those in the southern and western regions of the country, all of which have statistically significant differences with the north, east, and central regions which have average opinions of EVs below the aggregate mean, though the difference is only statistically significant for the north.

In education levels a sizable difference in EV appraisal appears. Both respondents with a primary school education and those who have completed secondary school rate EVs lower (mean 4.53 and 4.62, respectively) than do those with a university or college degree (5.23). Age groups also responded with varying levels of support, with those under 35 showing significantly higher support than those between ages 46-75. Those over 75 show a slight increase. In some ways opinions of EVs by age are the opposite of ownership of EVs by age, with ownership lower at the extremes and higher in the middle age brackets and opinions on EVs the reverse. Interestingly, a similar pattern holds for opinion on EVs by level of interest in politics: those at the extremes (extremely interested or uninterested) report higher support for EVs than those that report more moderate levels of interest in politics.

Finally, there is a significant gender difference in opinions about electric cars. Women have a mean opinion of 5.11 while amongst men the mean is 4.85 . Both are statistically different from the total mean at a $95 \%$ confidence level.

6. The NCP does not ask respondents about income. 


\subsection{Open-answer text responses}

Of 3,139 respondents asked for open-answer text data on EVs, roughly two-thirds wrote five words or less, with a full $25 \%$ writing only one word. The total corpus makes up just over 25,000 words.

When looking at who wrote more (or less), we find some differences in age groups. The youngest age bracket (18-25) and oldest two brackets (66 and up) wrote significantly more (averages between 9.1 and 10.3 words per response) as compared to the middle brackets that average between 6.6 and 7.8 words. The largest difference in response length, however, is by opinion of EVs where there is a clear skew toward writing more amongst those who have more negative opinions of EVs than positive. Here the negative to neutral categories (1-4) average roughly 10 words per respondent, while those having a very favorable opinion write on average just over half as much (5.9 words) and those of positive but slightly more tempered views average 6.8 ad 7.8 words. Thus, having an opinion that was one step more pessimistic in relation to EVs corresponded to almost one word longer response on average. In short, those with negative views expound on them at greater length than do those with positive, a recognizable human trait, no doubt.

\subsubsection{Word frequencies}

The most commonly used words over the entire corpus are given in Table 1. The most striking feature is that the two words 'environment' and 'environmentally-friendly' are far and away the most widely-used words to discuss EVs. These two words are mentioned over 1000 times, significantly more than any other words. Of the rest of the the top thirty most-used terms, a number mention issues with EVs that could be either negative or positive such as 'free', 'range', 'tolls', 'electricity', 'battery', 'charging stations', 'bus lanes'. Several of the words are clearly charged one way or the other: 'advantages', '(too) little', 'polluter'. Finally, the word 'Tesla' is extremely prominent and, we will show below, something of a lightening rod that is charged both with extremely positive and negative emotions.

The order of top word frequency is mostly the same for men and women. However, women respondents use the word 'environmentally-friendly' over twice as frequently as men. Use of the term is also correlated with higher education and age. Some $32 \%$ of the youngest respondents used the term whereas in the oldest age cohort the figure is less than half that. As might be expected, those who support the phase-out of new, fossil-fuelled cars from 2025 use the term "environmentally friendly" more frequently: 28 percent against 14 percent, respectively. The level of concern over climate change also correlates positively with the use of the term.

Further analysis of the top 20 words used by both men and women shows that women are slightly more likely to use words that are positive: "free", "good", and "advantages" 


\begin{tabular}{|c|c|c|c|c|}
\hline Rank & Word & Translation & Total Frequency & Response Frequency \\
\hline 1 & bil & car & 790 & 664 \\
\hline 2 & miljøvenn & environmentally friendly & 714 & 688 \\
\hline 3 & miljø & environment & 445 & 437 \\
\hline 4 & elbil & electric car & 236 & 188 \\
\hline 5 & tesl & Tesla & 229 & 227 \\
\hline 6 & batteri & battery & 192 & 180 \\
\hline 7 & fordel & advantage & 169 & 160 \\
\hline 8 & lit & little & 149 & 145 \\
\hline 9 & avgift & fee/tax & 147 & 146 \\
\hline 10 & bra & good & 144 & 137 \\
\hline 11 & kjør & drive & 139 & 128 \\
\hline 12 & bruk & use & 135 & 127 \\
\hline 13 & rekkevidd & range & 131 & 130 \\
\hline 14 & gratis & free of charge & 130 & 117 \\
\hline 15 & fremtid & future & 128 & 128 \\
\hline 16 & mye & much & 120 & 115 \\
\hline 17 & el & electric & 118 & 97 \\
\hline 18 & mang & many & 101 & 96 \\
\hline 19 & bompeng & road toll & 99 & 99 \\
\hline 20 & god & good & 99 & 92 \\
\hline 21 & forurens & pollute & 93 & 87 \\
\hline 22 & mer & more & 91 & 84 \\
\hline 23 & strøm & electricity & 90 & 88 \\
\hline 24 & kollektivfelt & bus lane & 90 & 90 \\
\hline 25 & økonomisk & economic & 89 & 89 \\
\hline 26 & stor & big & 82 & 78 \\
\hline 27 & mindr & less & 81 & 78 \\
\hline 28 & andr & other & 78 & 70 \\
\hline 29 & produksjon & production & 78 & 74 \\
\hline 30 & drift & operation & 77 & 77 \\
\hline
\end{tabular}

Table 1: Most commonly appearing words (stopwords removed) in the all responses and total number of responses containing the given words.

while men have a slightly greater relative use of words such as "range" (a word that generally implies unfavorable comparisons to gas motors) and "fees". "Batteries" and "production" also is among the most frequently used words by men but not women. As will be discussed below, these words are central to one of the main critiques of electric cars, namely doubt that electric cars are significantly better for the climate due to environmentally-damaging production of batteries. Finally, it is striking that other than the top two words that show very general (but wide-spread) recognition of broader climate effects, the rest of the frequency chart is taken up by what Noppers et al. (2014) call instrumental factors and personal advantages and disadvantages of electric vehicle use. 
Overall, words related to fairness - "subsidy", "exploit" and "opts out" - were found in 152 responses, against 2,989 containing none of these words. Logistic regression over gender, age, education, region and party show that women are significantly less likely to use words identified as related to fairness. In several model runs, older respondents are also shown to be more likely to mention such words when treating age as a continuous variable. However, no age group is significantly different from another, suggesting that the statistical relationship is not very robust. Region also shows little variation, although there are some model runs where either Western or Central Norway shows a significantly lower propensity to display fairness-related vocabulary. No effects are found from reported party vote intent nor from either attitudes toward the proposal to stop registration of new fossil-fueled cars from 2025 onward, or from the level of concern about climate change.

\begin{tabular}{|c|c|c|c|c|c|c|c|c|c|}
\hline & Token & Freq & Rel Freq & Token & Freq & Rel Freq & Token & Freq & Rel Freq \\
\hline 1 & envir fr & 55 & 1.114 & envir fr & 69 & 1.242 & envir fr & 590 & 4.064 \\
\hline 2 & battery & 51 & 1.033 & envir & 68 & 1.224 & envir & 328 & 2.260 \\
\hline 3 & envir & 49 & 0.992 & EV & 51 & 0.918 & tesla & 166 & 1.144 \\
\hline 4 & $\mathrm{EV}$ & 45 & 0.911 & battery & 50 & 0.900 & EV & 140 & 0.964 \\
\hline 5 & much & 42 & 0.850 & tesla & 42 & 0.756 & good & 120 & 0.827 \\
\hline 6 & little & 37 & 0.749 & much & 38 & 0.684 & advantg & 115 & 0.792 \\
\hline 7 & pollute & 29 & 0.587 & fee/tax & 36 & 0.648 & battery & 91 & 0.627 \\
\hline 8 & all & 27 & 0.547 & free & 36 & 0.648 & range & 90 & 0.620 \\
\hline 9 & advantg & 23 & 0.466 & little & 32 & 0.576 & drive & 90 & 0.620 \\
\hline 10 & use & 23 & 0.466 & advantg & 31 & 0.558 & fee/tax & 89 & 0.613 \\
\hline 11 & pay & 23 & 0.466 & many & 30 & 0.540 & use & 82 & 0.565 \\
\hline 12 & fee & 22 & 0.445 & use & 29 & 0.522 & future & 82 & 0.565 \\
\hline 13 & other & 22 & 0.445 & range & 28 & 0.504 & little & 80 & 0.551 \\
\hline 14 & drive & 22 & 0.445 & drive & 27 & 0.486 & free & 79 & 0.544 \\
\hline 15 & good & 22 & 0.445 & power & 25 & 0.450 & economic & 68 & 0.468 \\
\hline 16 & tesla & 21 & 0.425 & pollute & 24 & 0.432 & rd toll & 67 & 0.462 \\
\hline 17 & prod & 21 & 0.425 & come & 24 & 0.432 & operatn & 67 & 0.462 \\
\hline 18 & people & 20 & 0.405 & more & 22 & 0.396 & less & 65 & 0.448 \\
\hline 19 & many & 18 & 0.364 & other & 22 & 0.396 & bus lane & 62 & 0.427 \\
\hline 20 & like & 16 & 0.324 & bus lane & 21 & 0.378 & good & 61 & 0.420 \\
\hline
\end{tabular}

Table 2: Most frequently occurring words by category of EV opinion.

Abbreviations: "envir fr" = "environmentally friendly" ("miljøvennlig"); "envir" = "environment"; "advantg" = "advantage".

Analyzing word frequency by reported opinion of EVs gives us a better idea of the positive and negative valences given to words used by survey respondents. There are a number of ways to visualize this. Table 2 shows most frequently occurring words, pooled by those positive, neutral, or negative to EVs (based on numerical opinions of EVs). Table 5 in the appendix shows top 2-gram (that is two-word combinations) frequencies across 
said categories. Both make clear that while use of words "climate" and "climate-friendly" is observed across categories at or near the top of word frequencies in terms of rank, its frequency is far greater among those who rate EVs highly than those who do not. Furthermore, we see in Table 5 in the appendix that many occurrences of "environmentally friendly" are actually negated - those rating EVs lower actively contested the characteristic seemingly most valued by those positive toward them. Interestingly, those that might be presumed somewhat neutral - those appraising EVs at 4 on the seven point scale exhibit use of both 'not environmentally-friendly' and 'good for the environment' 2-grams roughly in equal degrees 7 Regardless, as clear from the word frequency charts, words "environmentally-friendly" and "environment" appear roughly as much as other highranked words among those who have a lower opinion of EVs, those rating EVs at a 5 on the 1-7 scale use them more and those rating EVs at a 6 or 7 use the terms significantly more. Those with the highest opinion of EVs use the term "environmentally-friendly" over three times as much as next most frequent term not including "environment."

\subsubsection{Topics}

While we were not able to fit a topic model to our corpus, general topics can be extracted by close readings guided by word frequencies. This "blended reading" approach identified two meta-topics among those with lower opinions on EVs. First, words "free", "pay", "free-loader", "parking", and "toll" are associated with an argument that those with EVs are free-loading on the rest of society as they unfairly avoid paying tolls and parking fees while putting the burden of paying on others. This is frequently associated with claims of injustice, specifically that EVs cost more thus it is wealthier members of society that shift the burden of behavior adjustment onto the less wealthy portions of the population. The word "Tesla" appears generally in this context among those with low opinions (ratings 1-3) of EVs. The second topic is the argument often heard in Norway that EVs are just as bad for the environment as fossil fuel-driven vehicles due to the high-polluting nature of electric battery production and disposal. Words "polluter", "battery", and "production" are terms associated with this topic 8 These two topics dominate those rating EVs at 1 or 2 out of 7 . They also show a great deal of overlap - these words that populate word frequency charts are often simultaneously part of both topics.

Significantly, neither of these topics are instrumental - that EVs are inconvenient or practically disadvantage the owner. Indeed, close reading shows both topics to be at least partially symbolic, though not reflectively symbolic. They are aimed at contesting the

7. Our small corpus means that especially n-grams among those with negative opinions toward EVs are small-N. Close readings will be added to the analysis below.

8. When words are sorted by term frequency-inverse document frequency, which is designed to highlight words heavily used by one group that are relatively less-used by others, terms such as "trick" also appear among top words giving even more weight to this category (see Table 6 in the appendix). 
symbolic self-representations of those who own EVs. The second topic was used both to question the degree to which EVs actually are better for the environment and then, in many cases, to expose EV owners, specifically well-off EV owners, as symbolic frauds. Survey respondents that mobilized this topic argued that EV owners want to display their virtue but are actually no better than anyone else because the production process leads to equally as much damaging effects as all other cars. One respondent wrote that she thinks of "a Tesla that weighs a ton and has stud tires [and] pollutes more than a diesel car". Another states "people purchase EVs because of tolls and taxes, not because they are, allegedly, environmentally-friendly. And what about total energy use, from production to destruction, of batteries," while another says EV owners "think they are environmentally-conscious but they're not... think about what it takes to build such a car" and one who calls EVs "climate-villains [klimaverstinger], free-loaders."

In the case of the first topic, the claim is both towards distributional injustice (making the less wealthy pay) together with the assertion that EV drivers, far from being virtuous, are simply leeching off the rest of society. This constitutes as type of symbolic attack. Thus one respondent writes of "free-loading cars that don't pay their own tolls or ferry charges in relation to the space that they still take up." Another associates EVs with "Tesla, rich free-loaders that want to drive in the bus lane" and another that says EVs are "free-loaders that we must pay for."

Among those with a below-average but slightly higher opinion (3 and 4 of 7) the distributional argument largely drops out, replaced by the appearance of instrumental factor. These groups often speak of the advantages and drawbacks of EVs using words such as "range", "fees", "advantages", and "electricity". The words "tolls" and "Telsa" appear in these arguments as well but mostly in different topics and with very different valences. Here they are connected not to arguments about distributional justice but to instrumental discussions of the practical advantages or simply associations without obvious normative judgements attached to them. Those rating EVs at 3 of 7 still have words associated with the argument that EVs are environmentally damaging among the most frequently used words, while the topic recedes among those in category 4.

Of those rating EVs at 5, 6, or 7 out of 7, the association of EVs with being environmentallyfriendly overwhelms all others. This non-instrumental category, however, is quite shallow, largely made up on just one or two words ("environmentally-friendly" and "environment") and frequently appearing in answers that are only one or two words long. It is extremely popular but a very vague association. Moving beyond this, we see from the frequency tables and have verified by hand-reading that instrumental factors dominate the rest of discussion. Here we might differentiate between technical advantages and disadvantages of EVs, associated with terms "range", "electricity", and advantages of EVs due to policy decisions in Norway ("cheap", "tolls", "fees"). 
Toward the higher end of positive opinions a final topic emerges - that EVs represent the future. This is a topic that might be both instrumental as well as environmental and symbolic. Close readings show that the word "future" occurs frequently as single-word associations and when embedded in longer thoughts often focus on social and planetary gains ("the future of transport" or "future-looking, we should all move over to it [EVs]"). It is not hard to think that the topic of the future is a source of significant symbolic worth, showing the EV owner as not only doing good for the environment and slowing climate change but at the crest of the wave of the future. It is the fifteenth most commonly occurring non-stopword in the corpus (in 128 responses) and appears with increasing frequency the better a person's opinion of EVs, as shown in Figure 2 below.

The keyness visualization in Figure 1 of words used by those ranking EVs highly and those with negative opinion of them underline the discussion above. Among those viewing EVs highly, the words "environmentally-friendly" and "future" are among the most over-represented, followed by several terms like "range", "bus lane and "charging statation" associated with more instrumental concerns. Words most setting those with negative opinions apart are those central to the two negative topics identified above contesting that EVs are, in fact, good for the climate and that EVs are free-loading on the rest of society.

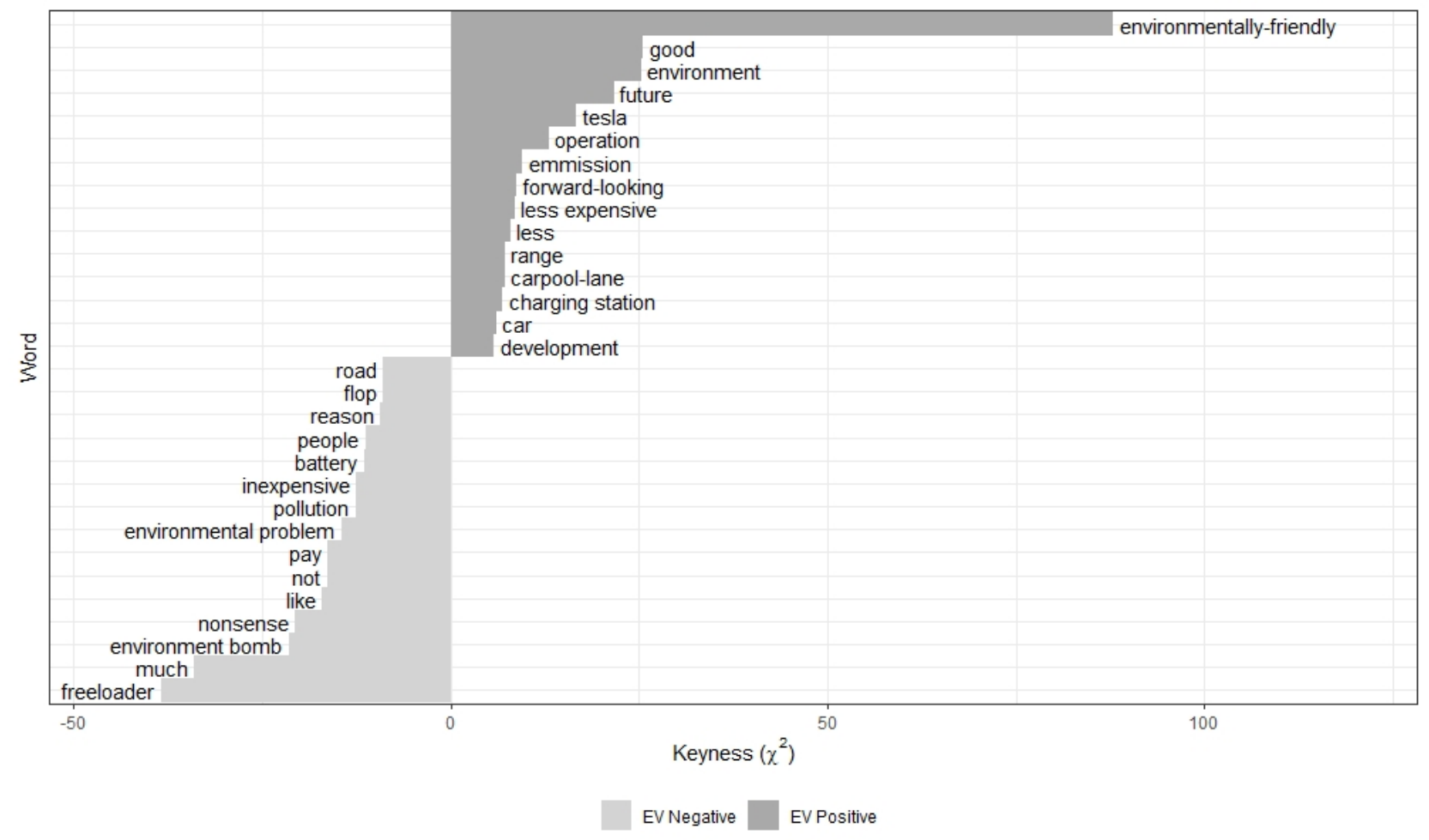

Figure 1: Keyness comparison of vocabulary used by those rating EVs 5-7 (target) and 1-3 (reference).

A final visualization of vocabulary used in responses is shown in Figure 2 , which 
displays average opinion on EVs given by respondents who employ each of the 50 most frequent terms. This too bears out the above analysis, showing at the high end of opinion vocabulary biased towards amorphous topics of the future and environmentalfriendliness. Lower down the scale instrumental reasoning dominates while at the most negative ends we see evidence of the two topics identified above - critique of EVs due to their hypocritical environmental unfriendliness and the word "pay" closely linked to arguments that payment for climate mitigation in unequally shared.

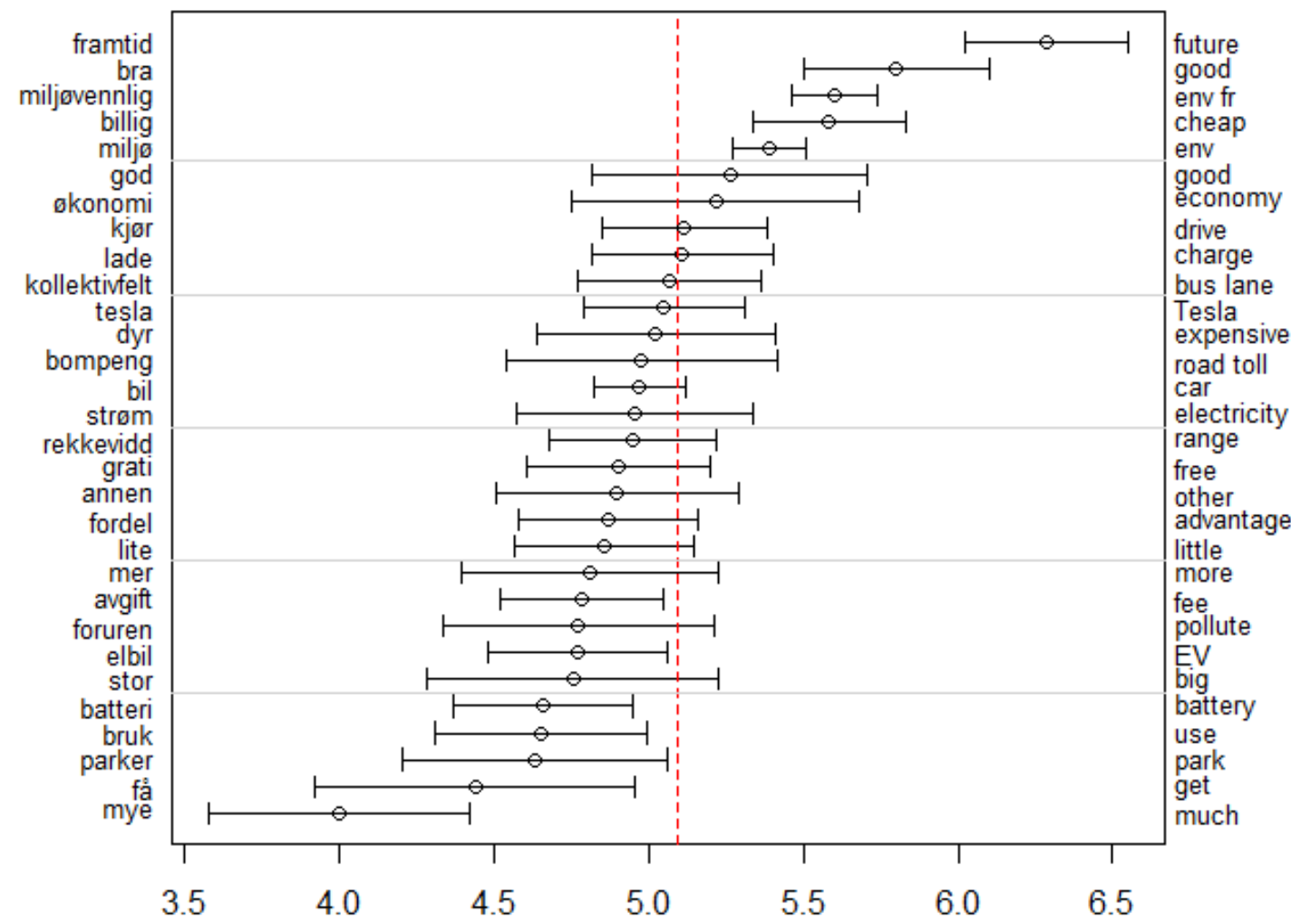

Positive/negative feeling toward EVs

Figure 2: Most frequently used terms and the average opinion of EVs of respondents who use them.

The number of observations for each term may be higher than the number of occurrences of that term, e.g., as responses containing the term "environmentally-friendly" also contribute to averages for the string "environment."

\subsubsection{Multi-valent and strongly weighted terms}

Having located words that seem to be particularly polarizing, we now move to a close reading of those words. Words identified with the first critique of electrical vehicles identified - that those who have the means to purchase them are free-loading on the rest of society - is associated with the words "free", "pay", "free-loader", and "toll".

The most charged word, "free-loader", appears in forty responses. The opinion of EVs 
among these respondents ranges from 1-7, but the average is clearly on the lower side with a mean of 3.02. Half of the responses are single word answers. Several of the responses mix positive and negative topics - such as one respondent, a male 26-35 year-old voter of the Socialist Left party (known for their active stance in climate mitigation and concern with economic inequality) who rated EVs 7 out of 7 but whose first thoughts in hearing the word electric vehicle were "the cheap/asocial (kjipe) Tesla owners who are dead-rich and free-load on the state." He went on, however, to state that EVs are the future and discussed instrumental factors (range, charging stations, function in cold weather) that will need to improve before EVs are more widely adopted. Several other respondents used the word "free-loader" while also reported positive opinions of EVs.

The bulk, however, using the word have a low opinion of EVs. For the most part responses using the word accuse EV owners of using the same infrastructure but not paying for it ("a car is a car and therefore [EV owners] should pay tolls and ferry charges"). One response brings up inequality in relation to residence ("all drivers in cities should have EVs then we in the country-side can use the gas-powered vehicles we rely on... cities have public transportation"). There is also resentment at the positive self-image of EV owners. This is somewhat implicit in the word "free-loader" but made explicit in several responses. One respondent described EV owners as "audacious [frimodige] drivers who believe they have more rights in traffic than they actually have in relation to other drivers" and another who reported the first thing to come to mind when hearing the word $\mathrm{EV}$ is "free-loaders who only think about themselves!!" and another described them as "free-loaders who hide behind the climate".

If we look at responses using words associated with the charge that EVs are bad and perhaps just as bad for the environment as EVs, here too we see a large overlap between topics. 142 answers mention the word stem "pollut-". This word is associated with both social goods that EVs provide (less overall air and $\mathrm{CO}_{2}$ pollution) and more pollution in the form of production of batteries. Which meaning the respondent is using can be difficult to assess with computational methods (using n-grams to bundle phrases such as "less polluting" and sentiment dictionary methods would be a start but would ultimately still give a high rate of mis-identification especially because many respondents do not even use full sentences). Our corpus is small enough that we can use computational methods to locate words of interest and read the individual responses by hand.

Roughly half of responses using the stem "pollut" are positive toward EVs (pollute less) and the other half are negative. Discussion of EVs as polluters (average opinion of EVs among respondents using this word stem is 4.59 , slightly above the mode score of 4 but below the mean of 4.98 . This shows not only how meaning of similar words is highly dependent on how an individual speaker uses it but also that a major avenue of critique of those not in favor of EVs is precisely to attack what is supposed to be the most positive 
thing about EVs - their climate-friendliness. Many of the uses of this stem are intertwined with attacks on the motives and positive self-images of EV owners while others attribute high opinions of EVs with people who are not well informed (EVs polluting "more than people generally believe" is a phrase found in a number of responses). One respondent suggested that the popularity of EVs is due to "more religion than technical substance".

If we look at the stem "just" or "fair" (rettferd-), some 27 respondents use the word and it, too, is strongly correlated with low opinions of EVs. Average rating of EVs for those using a variant of the word just or justice is 3.78. Indeed, in all but one case the stem 'just-' appears negated in the form - "unjust" or "unfair" (urettferdig-). Here all responses go in the same direction - that it is unfair that owners of non-electric vehicles subsidize those who have EVs and don't pay tolls. The large majority of these responses are aimed at fairness in paying for roads - EVs cause wear and tear on roads just as much as any other car (more, in fact, some charge, due to battery weight) thus it is only fair that they pay the same tolls for up-keep 9 A minority of responses include charges of injustice due to income differences such as one who responds to the prompt "Tesla - support to those who have enough money". Another, unusually fully-articulated, response of a female 18-25 from the western part of the country states "I think EVs are good for the climate but I also think that some people buy EVs for advantages and not necessarily for the climate and I think also that it is unfair when ever more expensive tolls affect people who do not have money to buy an EV and that the richest thus avoid them". Another finds EVs to be the result of "unfair symbol politics".

The word Tesla is another word, like pollut-, that has a wide variety of sentiments attached to it. As noted, tesl- is one of the most frequent word stems in the entire corpus, appearing in 236 responses and its use tilts toward the favorable, with an average (mean) EV rating of 5.18 among those using the word stem tesl-. Of the 236, 135 are responses of four words or less, 76 made up of only the word Tesla. For one-word answers, and frequently other short answers as well, it is difficult for any reader - machine or human to read sentiment into the answer, though looking at the respondents' rating of EVs one can guess about the sentiment underlying the text response.

Another word strongly linked to justice concerns is the stem "rich-". Forty-eight respondents use this word with an average rating of EVs of 4.71, only slightly below the total sample average of 4.98 . This word can be mapped almost exclusively onto the topic of justice, with all responses regarding issues of justice, especially the state and other drivers subsidizing wealthy EV owners. As many note, in thinking of EVs they think of "car number 2 for rich people". Thus, while among those rating EVs highly justice is not the most frequently appearing topic, it is noteworthy that there is significant awareness and concern for elements of justice even among those who rate EVs highly.

9. This suggests a very different conception of the purpose of tolls on roads - to pay for upkeep or to change behavior, a distinction that is well-known and discussed within national and regional politics. 
Several respondents, however, rate EVs highly even though they display some concern for issues of fairness and pollution coming with EVs. One female Labor Party voter from Eastern Norway that scored her opinion of EVs at 6 out of 7 nevertheless reported, when thinking of EVs, "Tesla and wealth... and that it is completely impossible for me to ride this wave." Others associate Teslas with being "expensive" or being associated with "high class, with Teslas that receive too many advantages in traffic without a climate profit" or "for the rich of [capital city] Oslo and [its wealthy suburb] Bærum. Thus, despite overall high scores for EVs from those writing about Teslas, the use of the word Tesla in the majority of cases is connected with concerns about socioeconomic equality. Or as numerous respondents say, Tesla give advantages to those who already have them.

\subsection{Document similarities}

Finally, we move to considering the similarities and differences between text responses regarding EVs as a whole. We group responses together by category and report cosine distances between them in a matrix. Just as we did not note large differences in ratings of EVs (on 1-7 scale) between groups based on political party voted for in recent elections, neither do we see significant differences in vocabulary and document similarity (Figure 5 in the appendix). Other groups reveal either no interpretable patterns in cosine differences (such as, perhaps surprisingly, grouping by political orientation on a 1-11 left-right scale). In other cases, such as document similarity by age, we see, as indeed we should expect, that cosine distance finds the vocabulary used by age cohorts to be more and more different the greater the age difference gets.

To do this, we use the technique of cosine distance, which treats each document as a vector of words and then finds the cosine angle between any two vectors. This, then, is a bag-of-words approach where word order plays no role that merely compares the total number of distinct vocabulary words. The same document (or documents with the exact same number or proportion of the exact same words) will return a 1 and documents containing no words in common will yield a 0 .

Grouping by opinion of EVs might be expected to give the most meaningful information on vocabulary selection (Figure 3). The heat map matrix shows that documents are indeed more dissimilar the farther apart the authors' feelings about EVs are. Interestingly, we see differences between the similarities in responses at the top of the rating scale (5-7) and those at the bottom (1-3). Among those favorable toward EVs (at the top right of the heat map matrix), all groups produce aggregate responses that are .9 and greater in cosine distance, thus very similar. But among people rating EVs unfavorably (1-3 out of 7, at the bottom left of the matrix) we see much greater differences between groups.

This parallels with findings from the close reading, in which we found that positive opinions of EVs were frequently accompanied by short responses that are similar across 


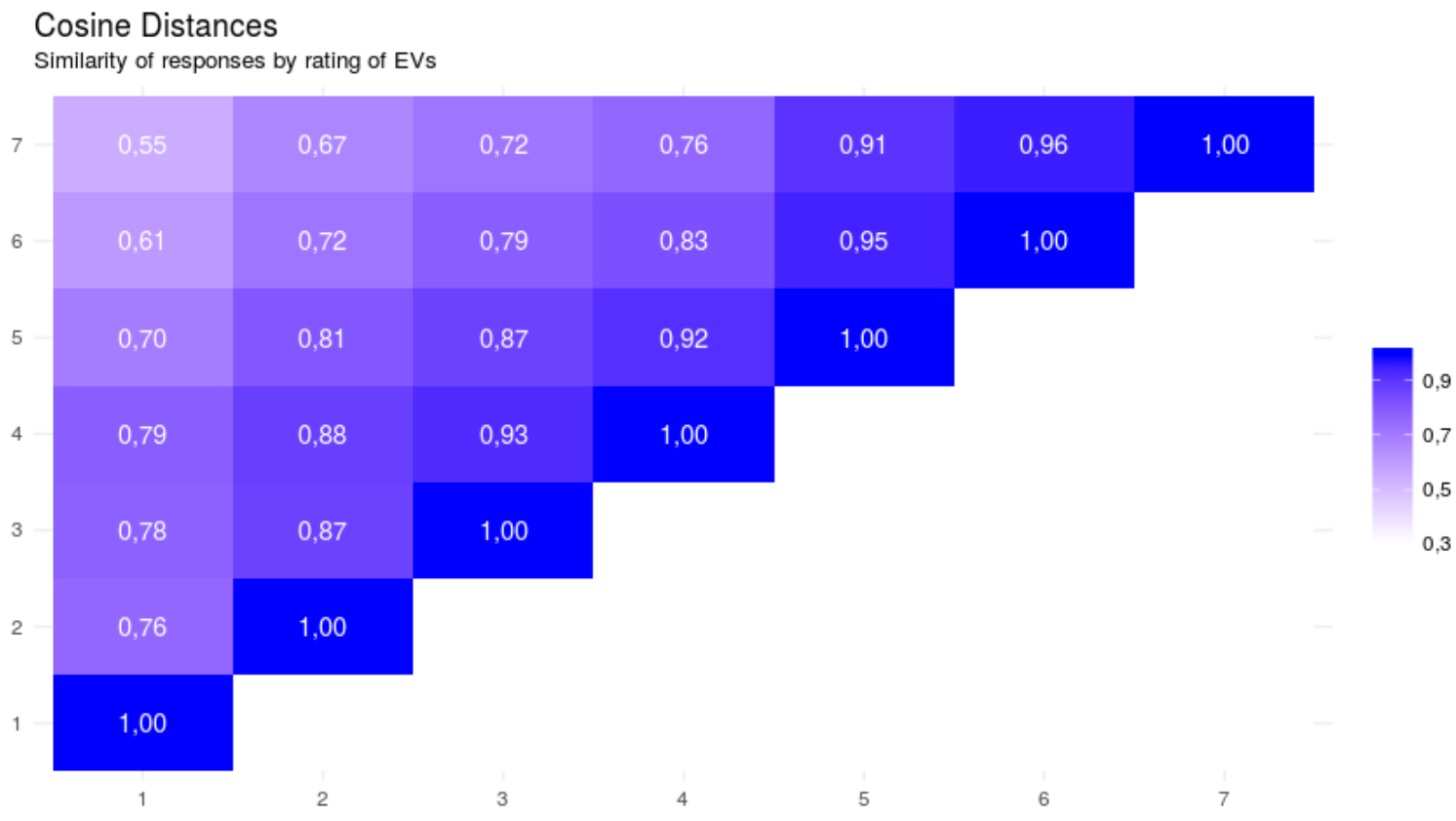

Figure 3: Cosine distance between responses grouped by opinion of EVs.

many respondents. Responses among people favorable toward EVs are more similar than those coming from people negative views. We might call this the "Anna Karenina effect" from Tolstoy's infamous first line of his classic novel.10 Those happy with EVs express themselves in similar ways - and, as noted above, at shorter length. Those unhappy demonstrate more diversity in their unhappiness.

We might also look to quantify lexical diversity within categories as well as between them. To do this a measure from NLP called Type-Token Ratio (TTR) can be computed giving a score of lexical diversity. We use a Moving-Average Type-Token Ratio (MATTR) which calculates TTR within a moving window of words over the entire document and produces the means of all TTRs (Covington and McFall 2010).11 This produces a table (Table 3) showing lexical diversity at its highest among those with more negative opinions of EVs. This, together with cosine distances and close readings again strongly suggests an Anna Karenina effect in opinions on EVs as articulated by a representative cross section of Norwegian society.

10. "Happy families are all alike; every unhappy family is unhappy in its own way." (Tolstoy 1877, 1)

11. MATTR is computed using the R package 'quanteda'. 


\begin{tabular}{cc}
\hline EV Rating & Diversity \\
\hline 1 & 0.7687 \\
2 & 0.7634 \\
3 & 0.7370 \\
4 & 0.7588 \\
5 & 0.7437 \\
6 & 0.7271 \\
7 & 0.7187 \\
\hline
\end{tabular}

Table 3: Moving-Average Type-Token Ratio (MATTR) with 100 word window.

\section{Discussion}

The data and analysis stemming from our examination of open-ended survey responses strongly supports Steg and De Groot (2012) and Noppers et al. (2014)'s argument about the importance of symbolic actions related to changed behavior and lifestyles in response to climate change. Behavioral change and preference formation in matters of climate change adaptation and mitigation are not made merely on the basis of material or instrumental utility. In addition to the kinds of "reflexive symbolism" located by other authors, we identify a strain of "contested symbolism", in which opponents of certain technologies or lifestyles - and the benefits associated with them - dispute the virtue of adopters. "Contested symbolism" disputes not only the general virtue in driving EVs with regard to fairness and equity but goes further to question the very essence of whether or not EVs are, on the whole, better for the environment or not.

The second popular topic associated with low opinions of EVs is directly tied to justice. Here the injustice of policies that favor EVs is double-headed. First, policies that benefit owners of EVs are disproportionately enjoyed by the rich, thus providing them with undue material benefits, while materially disadvantaging the already disadvantaged. Secondly, and in fact more prevalent, is an accusation of injustice stemming for principles of equal use. If EV owners use the same roads as everyone else, they should pay tolls and taxes for their building and upkeep. In this sense, the legitimacy of using tolls and congestion charges for purposes of climate change mitigation is implicitly disputed. If tolls are exclusively charged for the upkeep of transportation infrastructure, the use of said infrastructure without being required to pay is experienced as deeply unfair.

Both symbolic contestation and unfairness topics are concentrated at the negative end of opinions on EVs, yet there are some respondents across the spectrum that are influenced by them as well. These topics at the high end, however, are overwhelmed by a broad, catch-all and generally unarticulated notion "environmental-friendliness". A plausible hypothesis, though one difficult to test with this data set, is that broad, overarching phrases mean many different things, perhaps even mutually exclusive, to different people.

This leads to the last observation, that there is much more conformity and similarity in 
how those pleased with EVs speak about them than those who look disfavorable upon them. Those who react negatively to EVs write more and, not unsurprisingly, use a more varied vocabulary than those who view them positively, who often limit themselves to short, widely-shared and amorphous reactions. We have called this the "Anna Karenina effect," the idea those satisfied tend to express themselves similarly but dissent or critique is more disparate.

\section{Conclusion}

In this study, we relied an array of generally simple computational text analytic tools largely taken from Natural Language Processing that both informed and was informed by close, human reading of the texts. We found that simple word or n-gram counts were able to do many of the same things as topic models. The great advantage of these methods is that easier to understand and interpret - there is no black box of an algorithm that spits out results that can be hard to interpret and impossible to reverse engineer. These methods informed our manual processing of texts suggesting where and what to read, which in turn informed our decisions about further computational tests to run. Machine reading also enabled us to see patterns with covariables in a way that not possible through just reading. Finally, basic NLP tools could also play a role in validating and giving further evidence for and visualizing hypotheses.

Norwegians generally like EVs. In Norway today, it is those who favorably view EVs that have reason to be content with current policies. This could be both an asset for proponents of EVs seeking to mobilize broad political support, but also a weakness as such support might not be deep and could be more likely to fracture internally when concrete details are discussed. There is reason to believe this pattern could be repeated in other contexts as EV technology becomes more widespread. Norwegian economic incentives and policies encouraging EV adoption have been critical for their wide expansion in the country but the backlash suggests that not just state policies but the very understanding of EVs as environmentally beneficial is liable to come under attack.

Furthermore, both potential weaknesses in EV support and also some, still limited, recognition among those favorably viewing EVs of their potential downsides suggests some common ground for climate solutions that include but are not limited to EVs. Across the political spectrum and along the entire range of EV opinion, respondents suggested ways in which issues of fairness - wealthy and low-income, rural and urban, and other fault lines - might be bridged by expanding EVs in rural areas while encouraging better public transportation infrastructure in population centers, targeting economic incentives in ways that those with smaller incomes could partake, recognition of the real negative environmental impacts of EVs. 
Additional policy recommendations stemming from this study are that it could be beneficial to de-link payment for EVs and carbon reduction technologies from infrastructure use not connected directly to $\mathrm{CO}_{2}$ creation. At the very least, the idea that road tolls are a device to be used for political and social ends - as advocated by some - is seen by many to be unfair and potentially illegitimate. This topic was at least equally widespread as the topic of fairness and social equity, which has hitherto received more attention. Questions of legitimacy of use of certain policy instruments to achieve climate goals must be addressed. 


\section{References}

Barth, Markus, Philipp Jugert, and Immo Fritsche. 2016. "Still underdetected - Social norms and collective efficacy predict the acceptance of electric vehicles in Germany." Transportation Research Part F: Traffic Psychology and Behaviour 37:64-77. Accessed April 8, 2020.

Biresselioglu, Mehmet Efe, Melike Demirbag Kaplan, and Barbara Katharina Yilmaz. 2018. "Electric mobility in Europe: A comprehensive review of motivators and barriers in decision making processes." Transportation Research Part A: Policy and Practice 109:1-13. Accessed April 8, 2020.

Blei, David M. 2012. "Probabilistic topic models." Communications of the ACM 55 (4): 77.

Bockarjova, M., and L. Steg. 2014. "Can Protection Motivation Theory predict proenvironmental behavior? Explaining the adoption of electric vehicles in the Netherlands." Global Environmental Change 28:276-288. Accessed April 8, 2020.

Bubeck, Steffen, Jan Tomaschek, and Ulrich Fahl. 2016. "Perspectives of electric mobility: Total cost of ownership of electric vehicles in Germany." Transport Policy 50:63-77.

Covington, Michael A., and Joe D. McFall. 2010. "Cutting the Gordian Knot: The MovingAverage Type-Token Ratio (MATTR)." Journal of Quantitative Linguistics 17 (2): 94100.

Dodson, Jago, Terry Li, and Neil Sipe. 2018. "The socioeconomic equity dimensions of a transition in suburban motor vehicle fuel and technology." In Urban Sustainability Transitions, 233-249. Springer.

Goffman, Erving. 1990 [1956]. The presentation of self in everyday life. Nachdr. Anchor books. New York, NY: Doubleday.

Grimmer, Justin, and Brandon M. Stewart. 2013. “Text as Data: The Promise and Pitfalls of Automatic Content Analysis Methods for Political Texts." Political Analysis 21 (03): 267-297.

Joas, Hans, and Wolfgang Knöbl. 2014. Social theory: twenty introductory lectures. Translated by Alex Skinner. Cambridge: Cambridge University Press.

Jurafsky, Dan, and James H Martin. 2014. Speech and language processing. Vol. 3. Pearson London.

Koselleck, Reinhart, and Todd Samuel Presner. 2002. The practice of conceptual history: Timing history, spacing concepts. Stanford University Press.

Krause, Rachel M., Bradley W. Lane, Sanya Carley, and John D. Graham. 2016. "Assessing demand by urban consumers for plug-in electric vehicles under future cost and technological scenarios." International Journal of Sustainable Transportation 10 (8): 742 751. Accessed April 8, 2020.

Lemke, Matthias, Gregor Wiedemann, Andreas Blätte, Noah Bubenhofer, Andreas Henrich, Axel Philipps, Malte Rehbein, Joachim Scharloth, Bernd Schlipphak, and Manfred Stede, eds. 2016. Text Mining in den Sozialwissenschaften: Grundlagen und Anwendungen zwischen qualitativer und quantitativer Diskursanalyse. Wiesbaden: Springer VS.

Marche, Stephen. 2012. "Literature is not data: Against digital humanities." LA Review of Books 28.

Nelson, Laura K. 2020. "Computational grounded theory: A methodological framework." Sociological Methods E Research 49 (1): 3-42.

Noppers, Ernst H., Kees Keizer, Jan Willem Bolderdijk, and Linda Steg. 2014. "The adoption of sustainable innovations: Driven by symbolic and environmental motives." Global Environmental Change 25:52-62.

Potts, Christopher. 2010. "On the negativity of negation." Semantics and Linguistic Theory 20:636.

Rezvani, Zeinab, Johan Jansson, and Jan Bodin. 2015. "Advances in consumer electric vehicle adoption research: A review and research agenda." Transportation Research Part D: Transport and Environment 34:122-136. Accessed April 8, 2020. 
Ryghaug, Marianne, and Marit Toftaker. 2014. "A Transformative Practice? Meaning, Competence, and Material Aspects of Driving Electric Cars in Norway." Nature and Culture 9 (2): 146-163. Accessed April 8, 2020.

Schütze, Hinrich, Christopher D Manning, and Prabhakar Raghavan. 2008. Introduction to information retrieval. Vol. 39. Cambridge University Press Cambridge.

Scott, Mike, and Christopher Tribble. 2006. "Textual patterns." Key words and corpus analysis in language.

Sierzchula, William, Sjoerd Bakker, Kees Maat, and Bert Van Wee. 2014. "The influence of financial incentives and other socio-economic factors on electric vehicle adoption." Energy Policy 68:183-194.

Sovacool, Benjamin K, Johannes Kester, Lance Noel, and Gerardo Zarazua de Rubens. 2019. "Energy injustice and Nordic electric mobility: Inequality, elitism, and externalities in the electrification of vehicle-to-grid (V2G) transport." Ecological economics 157:205-217.

Statistics Norway. 2020. Bilparken. https://www.ssb.no/transport-og-reiseliv/statistikker/bilreg/aar.

Steg, Linda. 2018. "Limiting climate change requires research on climate action." Nature Climate Change 8 (9): 759.

Steg, Linda, and Judith IM De Groot. 2012. "Environmental values." In The Oxford handbook of environmental and conservation psychology.

Stoneman, Paul, Patrick Sturgis, and Nick Allum. 2013. "Exploring public discourses about emerging technologies through statistical clustering of open-ended survey questions." Public Understanding of Science 22 (7): 850-868. Accessed April 8, 2020.

Stubbs, Michael. 2010. "Three concepts of keywords." Keyness in texts: 21-42.

Tolstoy, Leo. 1877. Anna Karenina. Translated by Constance Garnett. New York: Random House.

Tvinnereim, Endre, Håvard Haarstad, Annika Rødeseike, and Véronique Bugnion. 2020. "Explaining public acceptance of congestion charging: The role of geographical variation in the Bergen case." Case Studies on Transport Policy.

van Vuuren, Detlef P, Elke Stehfest, David EHJ Gernaat, Maarten Berg, David L Bijl, Harmen Sytze Boer, Vassilis Daioglou, Jonathan C Doelman, Oreane Y Edelenbosch, Mathijs Harmsen, et al. 2018. "Alternative pathways to the $1.5^{\circ} \mathrm{C}$ target reduce the need for negative emission technologies." Nature Climate Change 8 (5): 391.

Veblen, Thorstein. 2005 [1899]. The theory of the leisure class: An economic study of institutions. Aakar Books.

Williams, Raymond. 2014 [1976]. Keywords: A vocabulary of culture and society. Oxford University Press. 


\section{Appendices}

\section{A Frequencies}

\begin{tabular}{rlr}
\hline & N-gram & Frequency \\
\hline 1 & bil & 402 \\
2 & miljøvenn & 255 \\
3 & ikk & 191 \\
4 & miljø & 189 \\
5 & tesl & 115 \\
6 & batteri & 113 \\
7 & elbil & 110 \\
8 & avgift & 82 \\
9 & fordel & 79 \\
10 & rekkevidd & 73 \\
11 & bruk & 71 \\
12 & lit & 70 \\
13 & mye & 70 \\
14 & el & 65 \\
15 & bra & 63 \\
16 & fremtid & 61 \\
17 & forurens & 51 \\
18 & stor & 47 \\
19 & kjør & 46 \\
20 & produksjon & 46 \\
\hline & & \\
\hline
\end{tabular}

\begin{tabular}{rlr}
\hline & N-gram & Frequency \\
\hline 1 & miljøvenn & 459 \\
2 & bil & 388 \\
3 & miljø & 256 \\
4 & ikk & 209 \\
5 & elbil & 126 \\
6 & tesl & 114 \\
7 & gratis & 95 \\
8 & kjør & 93 \\
9 & fordel & 90 \\
10 & bra & 81 \\
11 & batteri & 79 \\
12 & lit & 79 \\
13 & avgift & 65 \\
14 & bruk & 63 \\
15 & bompeng & 63 \\
16 & strøm & 62 \\
17 & god & 61 \\
18 & kollektivfelt & 60 \\
19 & mang & 59 \\
20 & rekkevidd & 58 \\
\hline
\end{tabular}

Men

Women

Table 4: Most frequently occurring words by gender 


\begin{tabular}{|c|c|c|c|c|c|c|c|c|}
\hline & N-gram & Frequency & & N-gram & Frequency & & N-gram & Frequency \\
\hline 1 & el_bil & 20 & 1 & el_bil & 20 & 1 & el_bil & 57 \\
\hline 2 & ikk_miljøvenn & 16 & 2 & ikk_miljøvenn & 11 & 2 & miljøvenn_bil & 45 \\
\hline 3 & lik_mye & 11 & 3 & bra_miljø & 11 & 3 & bra_miljø & 45 \\
\hline 4 & nr_2 & 8 & 4 & kort_rekkevidd & 10 & 4 & bil_drift & 44 \\
\hline 5 & all_batteri & 7 & 5 & gratis_parkering & 8 & 5 & mer_miljøvenn & 29 \\
\hline 6 & forurens_mye & 6 & 6 & bil_går & 7 & 6 & bil_går & 21 \\
\hline 7 & bil_ikk & 6 & 7 & mang_fordel & 7 & 7 & gratis_parkering & 21 \\
\hline 8 & økonomisk_fordel & 6 & 8 & økonomisk_fordel & 7 & 8 & økonomisk_fordel & 20 \\
\hline 9 & bil_nr & 6 & 9 & bil_ikk & 6 & 9 & kjør_kollektivfelt & 20 \\
\hline 10 & bil_nr_2 & 6 & 10 & andr_bil & 6 & 10 & går_strøm & 18 \\
\hline 11 & produksjon_batteri & 6 & 11 & dyr_bil & 6 & 11 & mang_fordel & 18 \\
\hline 12 & ikk_betal & 6 & 12 & kjør_kollektivfelt & 6 & 12 & kort_rekkevidd & 17 \\
\hline 13 & mang_fordel & 5 & 13 & diss_bil & 5 & 13 & bil_ikk & 16 \\
\hline 14 & spar_peng & 5 & 14 & gratis_bom & 5 & 14 & må_lad & 16 \\
\hline 15 & van_bil & 4 & 15 & mer_miljøvenn & 5 & 15 & nr_2 & 16 \\
\hline
\end{tabular}

Negative EV opinion

Neutral EV opinion

Positive EV opinion

Table 5: Most frequently occurring n-grams by category of EV opinion.

\begin{tabular}{|c|c|c|c|c|c|c|c|c|c|c|c|}
\hline & Word & TF-IDF & Doc Freq & & Word & TF-IDF & Doc Freq & & Word & TF-IDF & Doc Freq \\
\hline 1 & snylter & 25.51 & 16 & 1 & miljø & 28.43 & 67 & 1 & miljøvenn & 207.20 & 576 \\
\hline 2 & miljø & 15.78 & 46 & 2 & tesl & 25.85 & 41 & 2 & miljø & 145.40 & 324 \\
\hline 3 & miljøbomb & 12.28 & 8 & 3 & miljøvenn & 15.20 & 65 & 3 & tesl & 92.29 & 166 \\
\hline 4 & tull & 11.37 & 9 & 4 & batteri & 13.41 & 47 & 4 & bra & 51.08 & 114 \\
\hline 5 & batteri & 9.63 & 47 & 5 & avgift & 12.77 & 35 & 5 & fremtid & 49.63 & 82 \\
\hline 6 & tesl & 8.66 & 20 & 6 & gratis & 10.64 & 34 & 6 & drift & 41.95 & 67 \\
\hline 7 & miljøvenn & 8.50 & 47 & 7 & lading & 10.52 & 13 & 7 & rekkevidd & 34.58 & 90 \\
\hline 8 & lit & 8.44 & 34 & 8 & lit & 10.43 & 31 & 8 & avgift & 32.54 & 89 \\
\hline 9 & forurens & 8.11 & 28 & 9 & rekkevidd & 9.94 & 27 & 9 & fordel & 30.73 & 108 \\
\hline 10 & upraktisk & 7.89 & 6 & 10 & bompeng & 9.11 & 20 & 10 & strøm & 28.99 & 55 \\
\hline 11 & rekkevidd & 7.49 & 13 & 11 & kollektivfelt & 8.50 & 21 & 11 & økonomisk & 28.53 & 68 \\
\hline 12 & betal & 7.20 & 23 & 12 & fordel & 8.42 & 30 & 12 & framtid & 27.77 & 31 \\
\hline 13 & avgiftsfri & 7.16 & 6 & 13 & rekkeviddeangst & 8.35 & 5 & 13 & gratis & 26.93 & 71 \\
\hline 14 & forurensing & 7.07 & 7 & 14 & kjør & 8.17 & 25 & 14 & batteri & 26.25 & 86 \\
\hline 15 & mye & 7.04 & 38 & 15 & upraktisk & 8.07 & 5 & 15 & mindr & 25.24 & 63 \\
\hline
\end{tabular}

Negative EV opinion

Neutral EV opinion

Positive EV opinion

Table 6: Highest tf-idf scoring words by category of EV opinion

\section{B Cosine Distances}




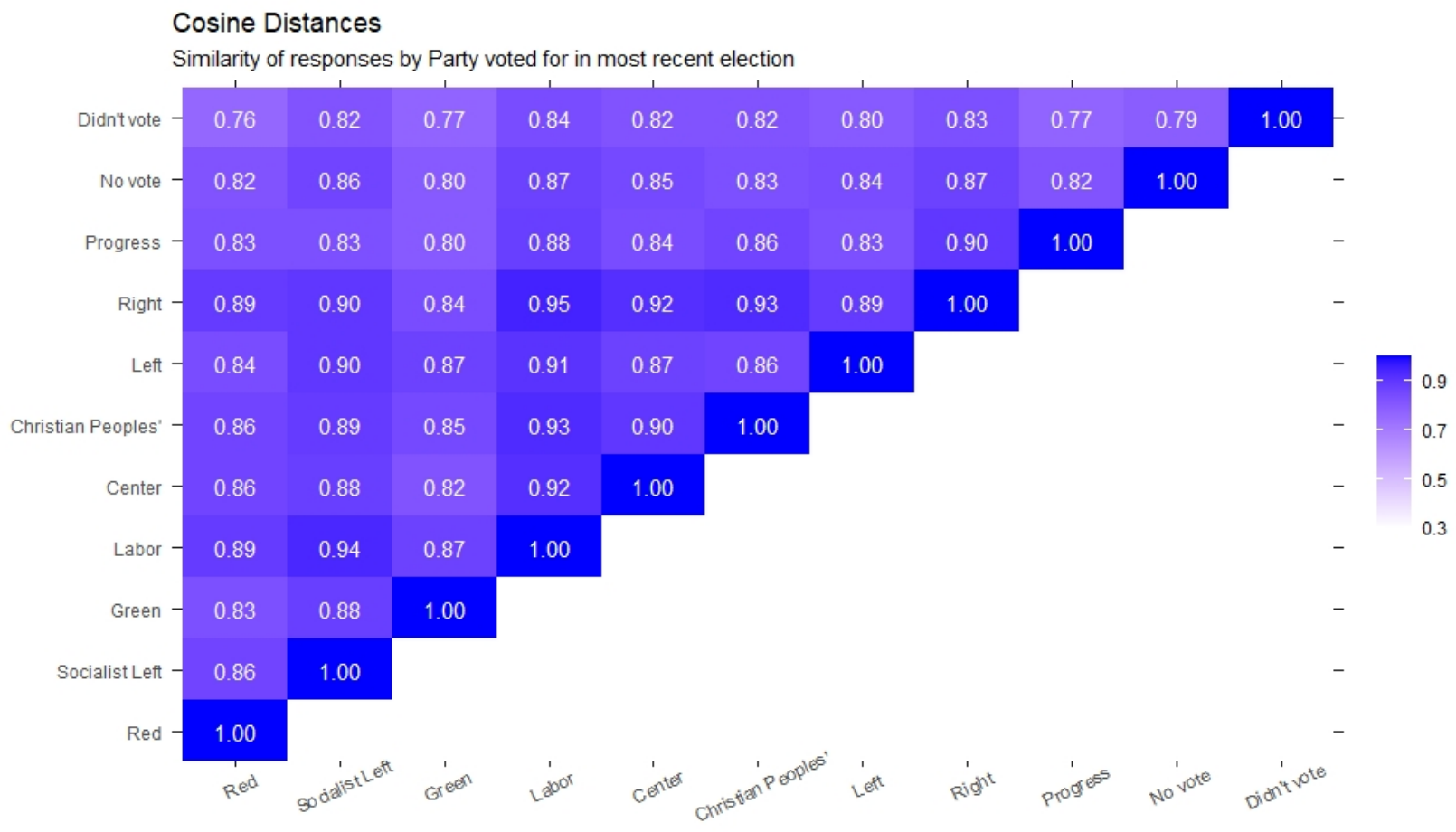

Figure 4: Cosine distance between aggregated responses by party voted for in recent election.

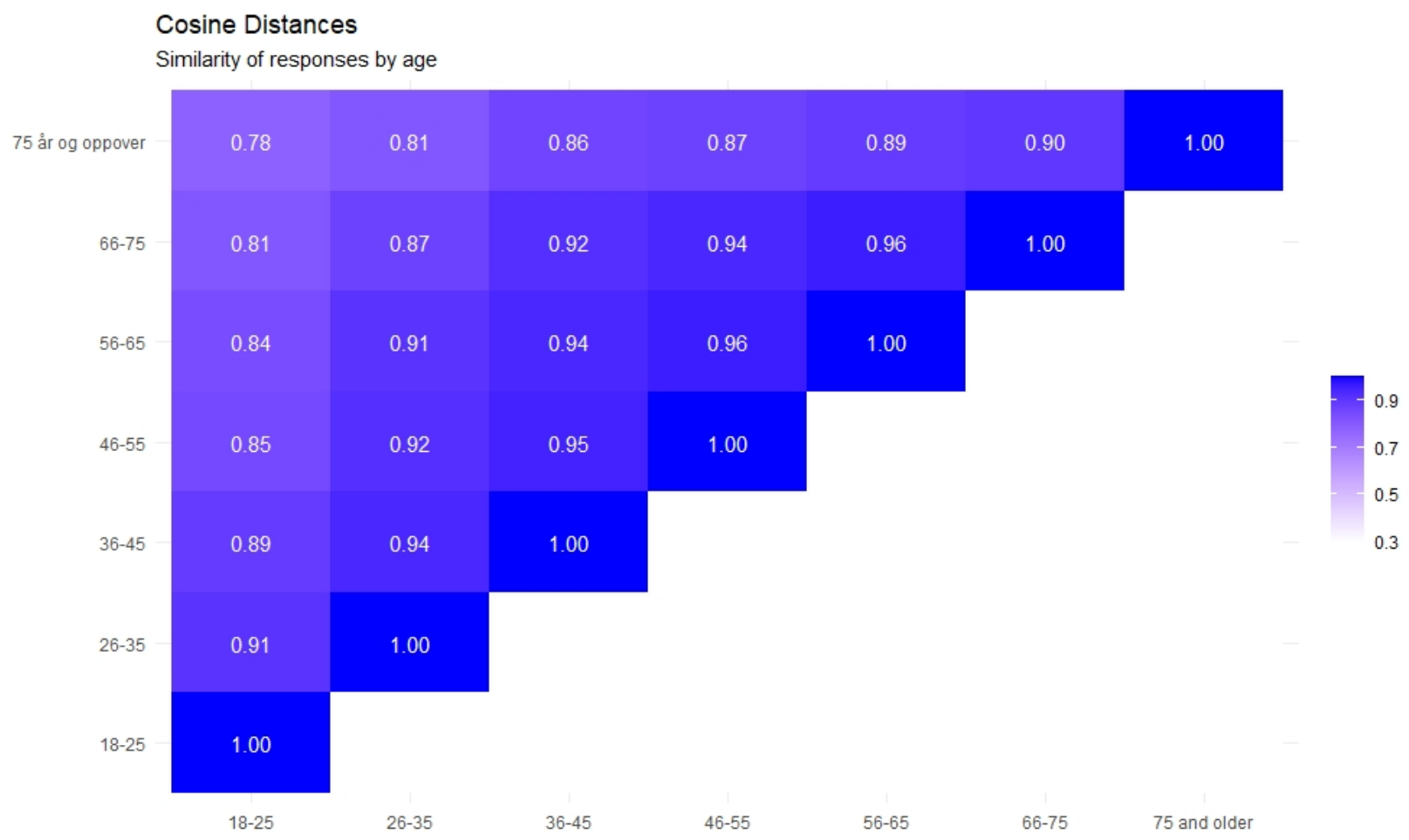

Figure 5: Cosine distance between aggregated responses by age. 